\title{
Communication between the elderly person and the Family Health Team: is there integrality ${ }^{1}$
}

\author{
Rita Tereza de Almeida² \\ Suely Itsuko Ciosak ${ }^{3}$
}

\begin{abstract}
Objective: to verify the forms of communication used in four Primary Health Units with Family Health Program teams in Porto Feliz, São Paulo, and how they impact in the care and control of the health of elderly people. Method: this qualitative study sought to capture the communication between elderly people and healthcare professionals. Interviews were conducted with 20 elderly people of both sexes. Results: from the discourses and observations, assertive communication and blocked communication emerged as the central analysis themes, the verbal and nonverbal elements of which, unveiled subjectivity of the communication process, of the local culture and of the psychosocial factors positively and negatively contributing to the healthcare for elderly people. The nursing teams of the Family Health Strategy showed forms of communication that favored the adherence of the elderly people to the care and control of their health. Negatives aspects did not have completely prejudicial consequences, however, should be avoided, in order to facilitate integral care to elderly people. Conclusion: it is worth reinforcing the need for improvement of the nursing team and other healthcare professionals regarding health communication as an innovative technology, bringing credibility to the health promotion and prevention programs with elderly users.
\end{abstract}

Descriptors: Primary Health Care; Communication; Aged; Family Health; Nursing.

\footnotetext{
${ }^{1}$ Paper extracted from master's thesis "Comunicação do Idoso e Equipe de Saúde da Família no Município de Porto Feliz-SP: Acesso à Integralidade?" presented to Escola de Enfermagem, Universidade de São Paulo, São Paulo, SP, Brazil. 2 Master's student, Escola de Enfermagem, Universidade de São Paulo, São Paulo, SP, Brazil.

${ }^{3} \mathrm{PhD}$, Associate Professor, Escola de Enfermagem, Universidade de São Paulo, São Paulo, SP, Brazil.
} 


\section{Introduction}

The aging of the Brazilian population is an achievement resulting from demands brought by the elderly population, in the context of the Brazilian National Health System (SUS). Created by Regulation No. 2.528 of 19 October 2006, the National Health Policy for Older Persons - PNSPI primarily aims for the recovery, maintenance and promotion of autonomy and independence of the elderly person, directing individual and collective health measures for this purpose, according to the principles and guidelines of the SUS. All Brazilian citizen 60 years of age or over are the target of this policy ${ }^{(1)}$. In this sense, the growth of this segment of the population has caused an increase in the concern and interest related to measures directed towards the demands of people over 60 years of age. A need is therefore shown for the implementation of appropriate public policies, aimed at promoting aging with quality of life ${ }^{(2)}$.

Elderly people, when seeking healthcare, expect something beyond attention to the illness. They want to be accepted and hope to establish bonds with the healthcare team in an environment of communication that allows autonomy, resolution and responsibility ${ }^{(3)}$. The most expedient consequence of the aging process for elderly people is to seek healthcare services and move through the different levels of care. For the neediest any difficulty becomes a reason to block or interrupt the continuity of the healthcare ${ }^{(4)}$. Thus, dialogue in the search for consensus is an essential element for the successful development of teamwork, as it enables the development of a communicative practice and "causes" the team to listen to others, which requires the establishment of a channel of communication(5).

Communication is part of human life ${ }^{(2)}$ and in the healthcare area it is essential for obtaining valuable information for the therapeutic actions, although, in everyday life, many people have difficulty expressing themselves or interpreting the language of communication. It is observed that the healthcare team must exercise true communication, being attentive to the interpretation of verbal, and especially nonverbal, language, which is not always valued, but of great importance in the interlocution. When communication is effective, it is an excellent tool for the pursuit of integral care for the health needs. In the clinical practice, communication may have a strong influence on the satisfaction, the adherence to treatment and, consequently, the healthcare outcomes, suggesting the need for technical and human preparation for the professionals involved(6), especially in Primary Healthcare $(\mathrm{PH})$. The operational definition of the concept of communication in this study refers to the development of ways to interact effectively and efficiently, taking into account the biopsychosocial aspects related to each populational group.

Considering the shortcomings of studies related to the communication between elderly people and the Family Health Strategy (FHS) team, it is believed that this study will contribute to the visibility of the interactive process, as a source of resolvability for the healthcare needs of elderly people included in $\mathrm{PH}$ health programs. It should be highlighted that with the expansion of the FHS in recent years, in the Brazilian municipalities, this study has become relevant as it aims to verify the forms of communication used in $\mathrm{PH}$ and how they impact in the care and control of the health of elderly people.

\section{Method}

This is a descriptive and exploratory, qualitative study. Some quantitative evidence of a sociodemographic nature was used to characterize the individuals interviewed. Elderly people of both genders who met the following inclusion criteria participated in the study: to be 60 years of age or older, to be registered in the FHS team, to be able to express feelings and perceptions, and to agree to participate in the study by signing the Terms of Free Prior Informed Consent. The location of the study was the urban area of Porto Feliz (SP) and included four Primary Health Units (PHU), each with a FHS team, in places where there were higher concentrations of elderly people registered.

The number of participants required was obtained through saturation sampling. Sampling closure by theoretical saturation is operationally defined as the suspension of the inclusion of new participants when the data obtained begin to present, from the assessment of the researcher, a certain redundancy or repetition, with it not being considered relevant to persist in the data collection ${ }^{(7)}$. Thus, five elderly people from each FHS team were interviewed, totaling 20 elderly people, considering the understanding of the homogeneity, the diversity and the intensity of the information, reflecting the multiple dimensions of the object of study ${ }^{(8)}$.

The instruments used for the data collection consisted of a script for the direct observation containing the elements of the forms of verbal and nonverbal communication captured during the care to the elderly 
people, an instrument with closed questions regarding the sociodemographic conditions of the elderly people, and open questions for interviewing them. The statements were recorded and transcribed in their entirety by the researcher, and after a thorough reading of the records of the discourses, the data were interpreted according to the thematic analysis technique ${ }^{(8)}$. The data were collected between June and September 2011, after approval by the Research Ethics Committee of the School of Nursing of the University of São Paulo (Protocol No. 1032/211/CEP-EEUSP).

\section{Results}

Data analysis of the sociodemographic conditions of the 20 elderly people who participated in the study found that 15 elderly people lived in private households and were married, demonstrating that the conformation of family life was centered on marriage and the family formation pattern was the stable union. Considering the place where the interviews took place, the PHU with a FHS team had a predominance of women (14) who sought healthcare, being significantly higher than the number of men (6). However, in the age group between 70 and 79 years there was a greater number of men (5) relative to the number of women (3).

The elderly people were found to have low levels of education: four elderly people declared themselves illiterate, 14 had attended Elementary School until the 4th grade, and only two reported having completed Elementary Education. The family income declared by 19 of the elderly people individuals was between one and three minimum wages, with a total of 11 retirees (6 men and 5 women), and 9 reporting that they had not retired.

The discourses of the elderly people were identified by the letter $\mathrm{E}$ followed by a number related to the sequence of the interviews. From the repeated readings of the interviews and the observation reports, assertive communication and blocked communication emerged as analysis themes, classified as central analyzes themes ${ }^{(8)}$ that were related to forms of communication, with thematic units: verbal element and nonverbal element.

\section{Assertive verbal and nonverbal communication}

The nurses of the FHS healthcare teams selected for this study used the correct intonation of language, establishing a dialogue of acceptance, speaking clearly, pausing, and looking directly at each elderly person. The language originating from the region used by the elderly people did not interfere in the communication process, being respected by the healthcare team and considered in meeting the needs of the elderly people.

Positive aspects of the assertive communication, as appropriate language, reinforced by the demonstration of facial expressions such as smiling, look directly at the elderly people, and listening attentively, were captured during the observation of the care, particularly regarding the nursing team of the FHS. The facilitation of the verbalization of the elderly people was mainly viewed in the nursing actions, in which the elderly people could express themselves to report their healthcare needs without blocks or inhibitions, revealed in the statement of an elderly woman yes, I say everything, I ask about everything, if I do not understand I ask them to repeat, I have to ask, right? I question (E16).

Reciprocity of intent unveiled a validation of the comprehension on behalf of the elderly people, of the messages passed by professionals of the healthcare team, as revealed in the following speech of an elderly man ah I understand, I managed to understand everything, yes (E10).

The professionals of the FHS teams established strategies, inducing the elderly people to attend the $\mathrm{PHU}$ for the control of their health, by presenting the appointment card and using it to mark the date of the consultation with the nurse or the physician, even though the elderly people attend the consultations periodically, as one elderly man said my wife and I have this appointment card that they mark and I use it to not forget when I have to come (E4).

The telephone contact conducted by the nursing team to effect a rescheduling of the appointment or to schedule the attendance of the elderly person to evaluate the results of examinations, showed good use of this technology, promoting a strategy well-accepted by the elderly people, as noted in this discourse of an elderly man I always come, I never miss an appointment and if it is not possible on that day, they call me and remake it, this is good because we do not waste time going there (E16).

The low educational level of the elderly people reflected a cultural difference between them and the healthcare team professionals. This fact did not seem to be an obstacle to the understanding of the elderly people, as they clarified their doubts, as can be seen in the statement of an elderly man they seek help from us with whatever they need and we understand their guidance. When I cannot understand, I can ask (E12).

Facial expressions such as smiling, interest, and attention, were observed, with these forms of nonverbal 
communication expressed both by the elderly people and by nursing team, presenting demonstrations of reciprocity, signs of bonding, affection and respect between the interlocutors.

\section{Blocked verbal and nonverbal communication}

Blocked communication was portrayed by the lack of dialogue between a $\mathrm{PH}$ healthcare professional and a professional of the mid-level complexity, creating barriers in the healthcare, as the discourse of an elderly woman demonstrates I came here $(\mathrm{PH})$ with the new physician and he referred me to do surgery, but I think the surgeon (medium complexity service) was in a bad mood. He looked at the paper (referral and counter-referral note) and said about the physician who referred me: "That kid does these things, he knows nothing" (E5).

Absence of listening generated blocked communication, as this discourse of an elderly woman explains when I'm attended by the doctor, she just gives a prescription, she doesn't ask anything and then sometimes I need a little medicine, something that I'm feeling, sometimes I don't ask her because it can be strange (E13).

Gestures of irritation and aggression from the professional, accompanied by inappropriate language, were factors that generated blocked communication, revealing an inability of the professional of a medium complexity unit, resulting in the exposure and embarrassment of one elderly women, as exposed in her statement the surgeon tore up the referral note in front of me. I was startled and left there. These things like that we are older and have become more sensitive and continue with the same problems (E5).

A cultural difference between the majority of the elderly people and the healthcare professional study participants was observed, generating blocked communication, particularly related to the figure of the physician, which seemed to have affected the integrality of the healthcare. It was possible to capture blocked communication related to the "myth linked to the figure of the physician", when the elderly people reported being ashamed and embarrassed in front of the professional. This denoted being scared and having difficulty verbalizing their needs, either due to the attitude of the professional or the existing social barrier, as shown by the statement of an elderly woman sometimes I feel embarrassed by the doctor. Sometimes they treat us well, sometimes not, but I have often left there with doubts. No, no, no, I do not ask (E13).

The nursing teams of the FHS studied were facilitators of the healthcare for the elderly people.
However, to overcome the communication barriers revealed by this "myth linked to the figure of the physician", innovative strategies must be articulated aiming to obtain integrality in the healthcare for the elderly people.

\section{Discussion}

Another study ${ }^{(9)}$ highlighted a gender perspective for the comprehension of the patterns of male morbidity/ mortality and raised the question of the healthcare needs of men in the context of the sociocultural relationships in which they live. Healthcare needs, their presentation to the services by men, and how they are treated by the professionals constitute issues of the relationship between the exercise of masculinity and the practices of healthcare(10). However, a study carried out in the Epidemiology Department of the University of São Paulo, School of Public Health, on the epidemiological profile of male morbidity/mortality, concluded that the low demand for healthcare services is not only linked to the use of the healthcare services, but to the fact that care habits are more present in women than in men ${ }^{(11)}$. The conformation of the family life of the elderly people was centralized in the marriage, demonstrating that the pattern of family formation is the stable union, conferring a historical and cultural aspect.

The elderly people may present some difficulties in verbal communication, however, they may also be very aware and trained in decoding nonverbal communication, as they have already been through numerous experiences throughout their lives ${ }^{(12)}$. The baggage of knowledge is something inherited from the predecessors, is something can be added to personal experience, which can only be comprehended through externalized actions that form the basis of communication and the social relationship(13). In this sense, the healthcare team must be careful to use forms of verbal and nonverbal communication to meet the health needs of the elderly population. This should be directed towards integrality and can be made possible through assertive communication, which means sending a message according to an objective, consistency between feelings, thoughts and actions ${ }^{(2)}$.

It is noteworthy that in nonverbal communication, facial expressions can denote happiness, sadness, anger, indifference, contempt, shame, interest, and fear and that all these expressions may help to understand our interactions and relationships with elderly people ${ }^{(14)}$ Gestures of irritation, aggression, and the lack of listening 
on behalf of the professional cause embarrassment for the elderly person during the care and lead to treatment discontinuation, interfering in the dynamics of the communication and, as a consequence, the control of health, reflecting blocked communication.

Listening is one of the elements of the form of nonverbal communication that validate assertive communication $^{(2)}$. Being silent while the interlocutor is speaking cannot mean simply being speechless, if it is time for participation in the act of communication, if this means an opportunity to regain personal balance, and if this is the way chosen to give space to the interlocutor and open a "window" for a healthy relationship. The ability to listen has been related to a technological device of outstanding importance in the proposed humanization of health: the acceptance. Therefore, it is in the continuous interaction between user and healthcare services, in all the opportunities in which the possibility of listening to the other exists, that provides the acceptance(15).

Throughout the process of interpersonal communication, the body expresses a feeling underlying the message, with this expression being unconscious and also unconsciously perceived, often with greater clarity than the verbal expressions. The gesture, especially one of support, is a form of nonverbal communication that promotes assertive communication, because, as well as the facial expression, the gesture of support, reinforces the use of appropriate language and can simultaneously reinforce the attendance of the elderly people at the PHU. Blocked communication(2), in the same way as assertive communication, can direct the entire trajectory of monitoring the elderly person, possibly creating barriers in relation to the treatment, or in relation to the health unit itself, which may interfere with the communication process.

Noisy environments also constitute communication barriers $^{(2)}$ that interfere in the communication process in general, more so in healthcare, particularly with elderly people who may have some degree of hearing difficulty due to the aging process. However, among the main communication barriers, the human aspects are highlighted, which include culture, temperament, regionalism, social class, emotions, and perceptions, among others, and can be defined as psychosocial barriers. The "myth linked to the figure of the physician" seemed to affect the loyalty of the elderly people to the $\mathrm{PHU}$, as well as the pursuit of access to other levels of care, thus hindering the integrality of healthcare and health promotion for the elderly people.
Regarding technology, in general, this is a resource that acts as a facilitator, extending the capabilities of the individual, providing security and flexibility while preserving and organizing data and producing information. Thus, technology is not merely a resource of the individual, but also of the social group ${ }^{(16)}$.

Healthcare, respecting the principle of integrality, displaces the health practice of intervention/ medicalization for the care. However, the verticalization of the system creates some obstacles favoring the fragmentation of the work, because there is still a lack of communal effort between $\mathrm{PH}$ and the medium and high complexity care, favoring the lack of dialogue between the professionals ${ }^{(17)}$ and hindering the attainment of the results of the work.

The conscientization of the healthcare professional regarding the use of forms of assertive communication must occur to facilitate the verbalization of the elderly people, facilitating therapeutic treatment and consequently creating bonds, leading to health control. Therefore, in the humanization of actions, the healthcare professionals should be alert to perceive the SUS users with their subjectivities, needs and fear of verbalizing desires or saying something that the professional does not like, attitudes that result in passively accepting what the professional imposes, which, in the majority of cases, can lead to adverse health effects ${ }^{(17)}$.

Concerning the appointment, this may be a positive factor in the organization of the healthcare services, however, it seemed to become an obstacle for some elderly people, generating dissatisfaction with the care, often creating a barrier to adherence to the control of their health, as the elderly people did not like to have a set day to attend the health unit, preferring to go to PHU when they were unwell. Communication as the capacity for dialogue among the workers of the team and between them and the clients allows the work process itself to constitute an instrument to produce coresponsibility, resolvability and autonomy in the clients for transforming the purposes into the product(18).

Lack of conscientization of the elderly person regarding the need for periodic control of the health requires the nursing team of the FHS to perform effective communication considering the local culture, psychosocial factors and the subjectivity of the communication process, which may contribute to a change of attitude in the elderly person. In contrast, the lack of awareness of some healthcare professionals, regarding the appropriate use of forms of communication in the care to elderly people, can compromise the quality 
of the healthcare and when these professionals impose blocked communication it may lead the elderly people to interrupt the therapeutic treatment.

The nursing teams of the FHS seek integral care broadly aimed at ensuring better life and health conditions in the context of the community, revealing forms of effective communication in the interaction between the elderly people, their family and the healthcare team. Interpersonal communication is the key component of nursing professionals to generate support for the family and make it their partner ${ }^{(19)}$. Thus, it is believed that nursing professionals, as well as other healthcare professionals, must demonstrate interest in the healthcare for elderly people, which requires warmth, affection, respect, commitment and ethics, contributing to the effectiveness of the communication process, the efficacy of the treatment and promoting quality of life for the elderly population.

\section{Final considerations}

This study found how the forms of communication can interfere with the care and control of the health of elderly people, showing the existence of positive aspects, with verbal and nonverbal assertive communication, as well as negatives aspects with verbal and nonverbal blocked communication. Thus, the forms of communication used in the interaction between elderly people and the FHS healthcare team were analyzed, which showed that the actions of integrality are not always present in $\mathrm{PH}$, or in the mid-level complexity healthcare. This weakens the integral care to the elderly people and constitutes a major challenge for the healthcare professionals in transforming the attitude of the elderly people who do not adhereto treatment.

Integrality in its conceptual breadth and complexity presents the need for studies involving $\mathrm{PH}$ and other levels of healthcare for the improvement of knowledge and care. Furthermore, it is important to articulate the nurses and other team members with other social apparatus in order to encourage intersectorality for the effectiveness of the healthcare. Considering that $\mathrm{PH}$ seeks health promotion, prevention and treatment of diseases and that the FHS is the fertile soil for the implementation of these actions, the articulation of knowledge related to the forms of verbal and nonverbal communication is necessary in meeting the healthcare needs of the elderly population, striving to obtain better quality of life.

\section{References}

1. Ministério da Saúde (BR). Atenção à Saúde da Pessoa Idosa e Envelhecimento. Série Pactos Pela Saúde. Brasília (DF): Ministério da Saúde; 2006.

2. Almeida RT. A comunicação do idoso e equipe de saúde da família no município de Porto-Feliz-SP: acesso à integralidade? [dissertação de mestrado]. São Paulo (SP): Escola de Enfermagem da Universidade de São Paulo; 2012. 103 p.

3. Santos AM, Assis MMA. Da fragmentação à integralidade construindo e (des)construindo a prática de saúde bucal no Programa Saúde da Família (PSF) de Alagoinhas, BA. Ciência Saúde Coletiva. 2006;11(1):53-61.

4. Costa MFBNA, Ciosak SI. Atenção Integral à saúde do idoso no Programa Saúde da Família: visão dos profissionais da saúde. Rev Esc Enferm Univ São Paulo. 2010;44(2):437-44.

5. Araújo MBS, Rocha PM. Trabalho em equipe: um desafio para a consolidação da estratégia de saúde da família. Ciência Saúde Coletiva. 2007;12(2):455-64.

6. Damasceno MMC, Zanetti ML, Carvalho EC, Teixeira CRS, Araújo MFM, Alencar AMPG. Therapeutic communication between health workers and patients concerning diabetes mellitus care. Rev. Latino-Am. Enfermagem. 2012;20(4):685-92.

7. Fontanella BJB, Ricas J, Turato ER. Amostragem por saturação em pesquisas qualitativas em saúde: contribuições teóricas. Cad Saúde Pública. 2008;24(1):17-27.

8. Minayo MCS. O desafio do conhecimento: pesquisa qualitativa em saúde. 11. ed. São Paulo (SP): Hucitec 2008; 384p.

9. Figueiredo WS. Masculinidades e cuidado: diversidade e necessidades de saúde dos homens na atenção primária [tese doutorado]. São Paulo (SP): Faculdade de Medicina da Universidade de São Paulo; 2008. 295 p. 10. Schraiber LB, Figueiredo WS, Gomes R, Couto MT, Pinheiro TF, Machin $R$, et al. Necessidades de saúde e masculinidades: atenção primária no cuidado aos homens. Cad Saúde Pública 2010;26(5):961-70.

11. Laurenti R, Melo-Jorge MHP, Gotlieb SLD. Perfi epidemiológico da morbi-mortalidade masculina. Ciencia Saúde Coletiva 2005;10(1):35-46.

12. Ministério da Saúde (BR). Cadernos de Atenção Básica. Departamento de Atenção Básica. Envelhecimento e saúde da pessoa idosa. Brasília (DF): Ministério da Saúde; 2006.

13. Schütz A. El Problema de la Realidad Social. BuenosAires: Amorrortu; 1974. 336 p. 
14. Silva MJP. A importância da comunicação verbal e não-verbal no cuidado domiciliar de idosos. In: Duarte YA de O, Diogo MJD, organizadoras. Atendimento domiciliar: um enfoque gerontológico. São Paulo (SP): Atheneu; 2000. p. 203-12.

15. Ayres JRCM. O cuidado, os modos de ser (do) humano e as práticas de saúde. Saúde e Sociedade. 2004;13(3):16-29.

16. Virgil J. Síntese da relação da tecnologia com o ser humano e a sociedade. Informação \& Informação. 2008;13(1):48-71.

17. Garcia TR, Egry EY, organizadoras. Integralidade da atenção no SUS e sistematização da assistência de enfermagem. Porto Alegre (RS): Artmed; 2010. 336 p. 18. Cardoso LS, Cezar-Vaz MR, Silva MRS, Costa VZ. The purpose of the communication process of group activities in the Family Health Strategy. Rev. Latino-Am. Enfermagem. 2011;19(2):396-402.

19. Pinheiro EM, Silva MJP, Angelo M, Ribeiro CA. The meaning of interaction between nursing professionals and newborns/families in a hospital setting. Rev. LatinoAm. Enfermagem. 2008;16(6):1012-8. 